\title{
Incidentalomas and other subclinical abnormalities of endocrine glands in Sri Lankans: An autopsy study
}

Katulanda P1,2,3, Gunatilake S. S. C ${ }^{4}$, Dissanayake H. A2, Katulanda G. W' ${ }^{5}$, Anthonis S ${ }^{2}$, Galappaththy S. L', Anupama N. H. P. J ${ }^{2}$, De Silva A. H. N², Serasinghe K. T. M. P. S ${ }^{2}$, Samarasiri D. P. U. T ${ }^{2}$, Wickramasinghe A. $\mathrm{R}^{2}$, Hettiarachchi H. A. C. $\mathrm{L}^{2}$, Priyani A. A. $\mathrm{H}^{6}$, Wijayaratne H. $\mathrm{D}^{6}$, Ratnaweera G. $\mathrm{G}^{6}$, Tennakoon A7, Somasundaram N. P4 , De Silva M. V. C

${ }^{1}$ Department of Clinical Medicine, Faculty of Medicine, University of Colombo, Sri Lanka

${ }^{2}$ Diabetes Research Unit, Faculty of Medicine, University of Colombo, Sri Lanka

${ }^{3}$ Cruddas Link Fellow, Harris Manchester College, University of Oxford, UK

${ }^{4}$ Diabetes \& Endocrine Unit, National Hospital of Sri Lanka, Colombo, Sri Lanka

${ }^{5}$ Department of Chemical Pathology, National Hospital of Sri Lanka, Colombo, Sri Lanka

${ }^{6}$ Department of Pathology, Faculty of Medicine, University of Colombo, Sri Lanka

${ }^{7}$ Department of Forensic Medicine, Faculty of Medicine, University of Colombo, Sri Lanka

\section{Abstract}

\section{Background:}

Incidentalomas of endocrine glands are a common problem in endocrine practice. Data on their prevalence are limited from South Asian settings.

\section{Objective:}

We aimed to describe incidentalomas and other histopathological abnormalities in an autopsy series of Sri Lankans.

\section{Methods:}

Consecutive autopsies performed at Judicial Medical Office, Colombo from December 2014 to December 2016 were screened and the deceased without a diagnosed endocrinopathy (except diabetes) were included in the study. Pituitary, thyroid, adrenal, pancreas and ovarian specimens were sampled and examined both macroscopically and under light microscopy with Haemotoxylin Eosin stain.

\section{Results:}

Among 441 autopsies (mean age 52.5 years, male $77.8 \%$ ) examined, pituitary, thyroid, adrenal, pancreatic and ovarian nodules were detected in $0.8 \%, 37.2 \%, 1.8 \%, 1.3 \%$ and $18.4 \%$ respectively. Thyroid neoplasms were present in $6.4 \%$, of which $87.5 \%$ were papillary carcinoma or papillary microcarcinoma and it was associated with background thyroiditis $(\chi 2=4.05, \mathrm{p}=0.04)$ or nodular thyroid enlargement $(\chi 2=32.68, \mathrm{p}<0.01)$. Thyroiditis was commoner in females, but malignancies showed no gender-predilection. No malignant lesions were identified in pituitary, adrenal, pancreatic or ovarian tissues.

\section{Conclusions:}

In this population of Sri Lankan adults, prevalence of thyroid incidentalomas, neoplasms and thyroiditis are comparable to published studies from the West. Papillary carcinoma or microcarcinoma was the commonest type and it showed a predilection to affect thyroid glands with background thyroiditis. Pituitary, pancreatic and adrenal incidentalomas and neoplasms were less prevalent. 
Key Words: Prevalence, Pituitary, Thyroid, Adrenal, Pancreas, Ovary, incidentaloma

Correspondence email: harsha@,clinmed.cmb.ac.lk

https://orcid.org/0000-0003-3903-9917

This is an open-access article distributed under the terms of the Creative Commons Attribution License, which permits unrestricted use, distribution, and reproduction in any medium, provided the original author and source are credited (CC BY 4.0)

\section{Introduction}

Incidentally detected tumours and subclinical disease of the endocrine organs have drawn much attention in current practice of endocrinology. Management of such lesions impose a clinical challenge to the physicians as the data on the prevalence, natural history and clinical significance of such lesions on morbidity or mortality are limited.

It is important to establish the prevalence and characteristics of such incidentalomas in the general population as such data may suggest that certain lesions may not progress to clinically significant disease during life. Autopsy series in western countries and India have reported the prevalence of these incidentalomas: pituitary 1.5-31.1\% (1-3), adrenal gland $1-32 \%(3-6)$ and pancreas (neuroendocrine) up to $10 \%$ (7). Although autopsy data are scarce, ovarian incidentalomas are documented as having a prevalence of $3.3-18 \%$ on imaging (8). The prevalence of incidentalomas tend to increase with age in all above series. The wide range of prevalence is of note, due to the variation in study population, and techniques used in the autopsy examination.

Thyroid related diseases are a common endocrine disorder, ranging from functional abnormalities to nodular thyroid enlargement. Due to the use of imaging modalities with high sensitivity, many thyroid anomalies are being detected incidentally, posing a challenge on clinical relevance and management strategy, especially in the context of thyroid nodules and papillary microcarcinoma. Autopsy studies on patients in whom clinical thyroid disease were not suspected previously showed a prevalence of nodular goitre $24-26 \%$, follicular adenoma $7-10 \%$, and thyroiditis of $4-9 \%(9,10)$. In similar studies, papillary microcarcinoma had shown a prevalence of $2-6 \%(9-14)$.

As the incidence and prevalence vary according to the population studied and for the fact that such data on incidentalomas and subclinical disease of endocrine organs are not yet available for the Sri Lankan population, we planned to conduct a descriptive autopsy study.

\section{Objective}

Aim of the study was to determine the prevalence, evaluate histological characteristics and clinical correlations of incidentally found tumours and other abnormalities of pituitary, thyroid gland, adrenal glands, pancreas and ovaries in autopsy specimen among the study population.

\section{Methods}

\section{Study design \& Study setting}

A cross-sectional descriptive study was conducted on consecutive post-mortem examinations performed at Judicial Medical Office, Institute of Forensic Medicine and Toxicology, Colombo, Sri Lanka from December 2014 to December 2016.

\section{Inclusion \& Exclusion criteria}

Individuals who had or deceased due to a known endocrine disease or problem except diabetes mellitus, who had previous surgeries on endocrine glands or hormone treatment for endocrine organ related disease, bodies with external signs of putrefaction at the time of the autopsy and bodies with damaged internal organs due to trauma were excluded from the study. 


\section{Ethical consideration}

Informed written consent was taken from next of kin of each deceased individual. Ethical clearance was obtained from Ethics Review Committee, Faculty of Medicine, University of Colombo.

\section{Data collection, Study instruments \& Measure- ments}

A structured interviewer administered questionnaire was used to record demographic and clinical details, administered by a trained interviewer. Information was gathered through medical records and interviewing next of kin of the deceased. Structured format was used to record post-mortem findings, completed by the judicial medical officer conducting the post-mortem. A third form was used to record the findings of pathological evaluation and was completed by the specialist histopathologists performing the examination. In case of discrepancy, consensus was reached by two histopathologists through re-evaluation and final decision was recorded in the database.

\section{Histological evaluation}

Specimens of pituitary gland, thyroid gland, adrenal glands, pancreas and ovaries were retrieved after meticulous autopsy and preserved in 10\% formalin.
Pathological evaluation was performed by specialist pathologists at Department of Pathology, Faculty of Medicine, University of Colombo, Sri Lanka. Specimens were examined for macroscopic abnormalities. Glands were cut in to thin sections $(2 \mathrm{~mm}$ for pituitary, $3 \mathrm{~mm}$ for thyroid and ovaries, $5 \mathrm{~mm}$ for adrenals and pancreas) and examined under light microscope with Haematoxylin Eosin (H\&E) stain by two independent specialist pathologists. All macroscopically abnormal regions were examined microscopically. In case of macroscopically normal tissue, entire glandular tissue of pituitary and representative sections of other glands (one each from left and right lobes of thyroid, one each from left and right adrenals, one section each from head, body and tail of pancreas and one each from left and right ovaries) were examined.

Histological diagnoses were based on standard criteria. In thyroid specimens, the diagnosis of papillary carcinoma was made on the presence of papillary carcinoma nuclear features \pm papillary architecture. Papillary carcinomas measuring $\leq 10 \mathrm{~mm}$ were designated as papillary microcarcinomas. Encapsulated follicular lesions were designated as follicular neoplasms. Differentiation of follicular carcinoma from adenoma was not made as the number of sections examined from the lesions is limited.

\section{Table 1 : Demographic characteristics of study participants}

\begin{tabular}{ll}
\hline \multicolumn{1}{c}{ Parameter } & Number \\
\hline Total population & 441 \\
Age (SD) (years) & $52.5( \pm 17.2)$ \\
Males (\%) & $350(77.8 \%)$ \\
Co - morbidities & \\
Diabetes (\%) & $53(19.1)$ \\
Hypertension (\%) & $80(22.9)$ \\
Ischemic heart disease (\%) & $48(13.7)$ \\
Family history & $1(0.3)$ \\
Thyroid malignancy (\%) & $8(2.3)$ \\
Thyroid disease (\%) & $2(0.6)$ \\
Ovarian malignancy (\%) &
\end{tabular}




\section{Statistical analysis}

Computer-based data entry was performed on gathered data and was analyzed using SPSS software (Statistical Products and Services Solutions, Chicago, USA) version 20.0.

Results

During the study period of two years, autopsy studies performed on 441 individuals were included in this analysis. Among those, $77.8 \%$ were males and mean age was 52.5 years (SD 17.2). Other clinic-epidemiological information is summarized in Table 1.

\section{Thyroid gland}

On macroscopic examination, thyroid gland was normal in 244 (59.9\%). Diffuse enlargement, multinodular goiter and solitary nodule were seen in

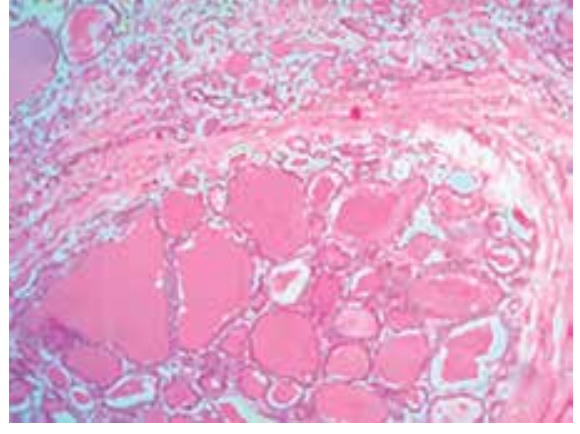

(a)

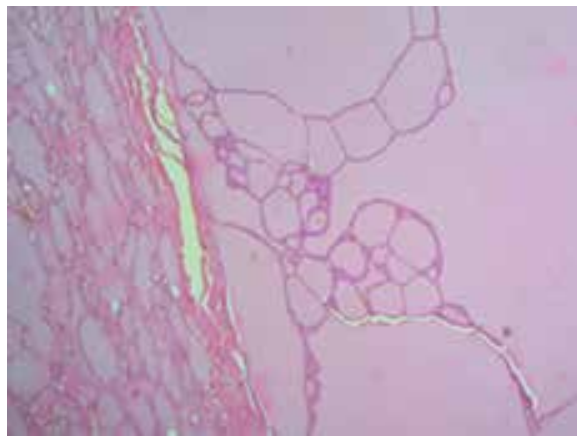

(b)

Figure 1: (a) Papillary thyroid carcinoma (x10); (b) Colloid nodule (x 10)

Table 2 : Macroscopic appearance of thyroid gland

\begin{tabular}{llll}
\hline & Males (\%) & Females (\%) & Total (\%) \\
\hline Normal & $201(62.0)$ & $43(51.8)$ & $244(59.9)$ \\
Diffuse goiter & $8(2.4)$ & $4(4.8)$ & $12(2.9)$ \\
Multinodular goiter & $51(15.7)$ & $23(27.7)$ & $74(18.2)$ \\
Solitary nodule & $64(19.7)$ & $13(15.6)$ & $77(18.9)$ \\
\hline
\end{tabular}




\section{Table 3 : Microscopic features of thyroid gland}

\begin{tabular}{|c|c|c|c|c|c|c|c|}
\hline Macroscopy & Normal & Colloid & Thyroiditis & $\begin{array}{l}\text { Hyperplastic } \\
\text { follicles }\end{array}$ & $\begin{array}{c}\text { Papillary } \\
\text { carcinoma }\end{array}$ & $\begin{array}{l}\text { Follicular } \\
\text { neoplasm }\end{array}$ & Total \\
\hline \multicolumn{8}{|c|}{ e } \\
\hline Males (\%) & $\begin{array}{r}157 \\
(81.0)\end{array}$ & $8(4.2)$ & $23(12.1)$ & $1(0.5)$ & $4(2.1)$ & 0 & 193 \\
\hline Females (\%) & $21(60)$ & $3(8.5)$ & $10(28.6)$ & 0 & $1(2.6)$ & 0 & 35 \\
\hline Total (\%) & $\begin{array}{r}178 \\
(78.1)\end{array}$ & $11(4.8)$ & $33(14.5)$ & $1(0.4)$ & $5(2.2)$ & 0 & 228 \\
\hline
\end{tabular}

Diffuse goitre

\begin{tabular}{|c|c|c|c|c|c|c|c|}
\hline Males (\%) & $3(37.5)$ & $5(62.5)$ & 0 & 0 & 0 & 0 & 8 \\
\hline Females (\%) & 0 & 0 & $4(100.0)$ & 0 & 0 & 0 & 4 \\
\hline Total $(\%)$ & $3(25.0)$ & $5(52.7)$ & $4(33.3)$ & 0 & 0 & 0 & 12 \\
\hline \multicolumn{8}{|c|}{ Multinodular goitre } \\
\hline Males (\%) & $2(3.9)$ & $\begin{array}{r}41 \\
(80.4)\end{array}$ & $3(5.9)$ & 0 & $4(7.8)$ & $1(1.9)$ & 51 \\
\hline Females (\%) & 0 & $\begin{array}{r}14 \\
(77.8)\end{array}$ & $4(22.2)$ & 0 & 0 & 0 & 18 \\
\hline Total $(\%)$ & $2(2.9)$ & $\begin{array}{r}55 \\
(79.7)\end{array}$ & $7(1.0)$ & 0 & $4(5.8)$ & $1(1.4)$ & 69 \\
\hline \multicolumn{8}{|c|}{ Solitary nodule } \\
\hline Males (\%) & $\begin{array}{r}12 \\
(21.1)\end{array}$ & $\begin{array}{r}28 \\
(49.1)\end{array}$ & $3(5.2)$ & $2(3.5)$ & $10(17.5)$ & $2(3.5)$ & 57 \\
\hline Females (\%) & 0 & $6(75.0)$ & 0 & 0 & $2(25.0)$ & 0 & 8 \\
\hline Total $(\%)$ & $\begin{array}{r}12 \\
(18.5)\end{array}$ & $\begin{array}{r}34 \\
(52.3)\end{array}$ & $3(4.6)$ & $2(3.1)$ & $12(18.5)$ & $2(3.1)$ & 65 \\
\hline Total & 195 & 105 & 50 . & 3 & 21. & 3 & 377 \\
\hline
\end{tabular}

* Complete data on microscopy were available in $93.4 \%$ (228/244) of normal, $100 \%$ of diffuse, $93.2 \%(69 / 74)$ of multinodular and $84.4 \%(65 / 77)$ of solitary nodules. Indicated percentages are out of the total number with histology data available.

$12(2.9 \%), 74(18.2 \%)$ and $77(18.9 \%)$ respectively. Solitary nodules were commoner among males, while diffuse goiter and multinodular goiter were commoner among females (Table 2). Among those with macroscopically normal thyroid glands, histology showed thyroiditis in $14.5 \%$ and papillary carcinoma in $2.2 \%$, all of which were papillary microcarcinoma. One third of the diffuse goitres showed thyroiditis while none had neoplastic features. Majority of multinodular goiters were colloid storing while $4(5.8 \%)$ of them had papillary carcinoma ( 1 of which was a microcarcinoma) and 1 (1.4\%) had a follicular neoplasm. Microscopy of $52.3 \%$ of solitary nodules showed colloid nodules, while 12 $(18.5 \%)$ and $2(3.1 \%)$ showed papillary carcinoma and follicular neoplasms respectively.

Of those papillary carcinomas 5 were microcarcinomas that co-existed with colloid nodules. Overall, $21(5.5 \%)$ thyroid glands harboured papillary carcinomas, of which 10 (47.6\%) were microcarcinoma. Prevalence of papillary carcinoma was not significantly different among males and females (5.9\% Vs. $4.6 \%, p=0.79)$. People with solitary nodules or 
multinodular goiters on macroscopic examination were more likely to have papillary carcinoma $\left(\chi^{2}=\right.$ $32.68, \mathrm{p}<0.01)$. Background thyroiditis was commoner in specimens with papillary thyroid carcinoma compared to those without, but this association was not statistically significant (Pearson $\chi^{2}=3.23$, $\mathrm{p}=0.07)$.

Thyroiditis was commoner in females $(27.7 \% \mathrm{Vs}$ $10.6 \%$ ). One female showed histological features of Hashimoto thyroiditis. Among those with thyroiditis, changes were focal in $16(32.0 \%)$. In people who had thyroiditis, $6(12.0 \%)$ and $1(2.0 \%)$ had papillary and follicular neoplastic foci respectively. All those papillary carcinomas were papillary microcarcinomas.
Among those with colloid goiters, co-existing thyroiditis, papillary carcinoma and follicular neoplasms were seen in $6(5.7 \%), 6(5.7 \%)$ and $2(1.9 \%)$ respectively.

\section{Pituitary gland}

Three hundred and seventy-three pituitary gland specimens were examined. On macroscopic examination, nodular enlargement of the pituitary was found in three individuals $(0.8 \%)$, two of which were pituitary adenomas $(0.6 \%)$. Pituitary calcification and fibrosis were found in the other specimen. One male had an adenoma in macroscopically normal pituitary. Therefore, overall prevalence of pituitary adenoma was $0.8 \%$.

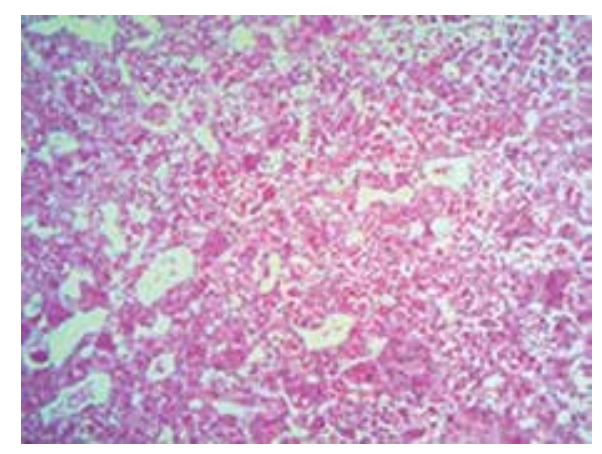

Figure 2 : Pituitary adenoma (x400)

\section{Pancreas}

Macroscopically, pancreatic focal lesions were found in six $(1.3 \%)$ individuals. Two had cystic lesions in the head of pancreas and four had solid lesions equally distributed in head and tail. Their features are summarized in Table 4. Among those with macroscopically normal pancreas, fatty infiltration, fibrosis and benign neoplasms were seen in 40 $(10.6 \%), 14(3.7 \%)$ and one $(0.2 \%)$ respectively. No malignant lesions were identified in any of the examined specimens. None of these individuals had extra-pancreatic endocrine organ nodules.Among people with diagnosed diabetes $(n=47)$, pancreatic microscopy was normal in majority $(76.6 \%)$ while fatty infiltration was seen in eight $(14.9 \%)$ (mild in 6, moderate in 1 and severe in 1) and fibrosis in three $(6.4 \%)$. Fatty infiltration was commoner in people with diabetes than without $(13.1 \%)$ but the difference was not statistically significant $\left(\chi^{2}\right.$ $=0.49, \mathrm{p}=0.48)$. Similarly, pancreatic fibrosis was also not significantly associated with diabetes $\left(\chi^{2}=\right.$ $0.008, \mathrm{p}=0.92)$. 


\begin{tabular}{|c|c|c|c|c|c|}
\hline & $\begin{array}{l}\text { Patient } \\
\text { characteristics* }\end{array}$ & Macroscopy & Site & $\begin{array}{c}\text { Size } \\
(\mathrm{mm}) * *\end{array}$ & Microscopy \\
\hline 1 & Male, $50 \mathrm{y}$ & Nodular & Head \& tail & $11 \times 9 \times 7$ & $\begin{array}{c}\text { Chronic } \\
\text { pancreatitis }\end{array}$ \\
\hline 2 & Male, 53 y & Cyst & Head & $10 \times 8 \times 5$ & $\begin{array}{c}\text { Chronic } \\
\text { pancreatitis }\end{array}$ \\
\hline 3 & Male, 44 y & Nodular & Head \& tail & $8 \times 9 \times 6$ & $\begin{array}{l}\text { Mild fatty } \\
\text { infiltration }\end{array}$ \\
\hline 4 & Male, 36 y & Nodular & Head \& tail & $9 \times 7 \times 5$ & $\begin{array}{l}\text { Mild fatty } \\
\text { infiltration }\end{array}$ \\
\hline 5 & Female, $72 \mathrm{y}$ & Cyst & Head & $8 \times 5 \times 12$ & $\begin{array}{c}\text { Normal pancreatic } \\
\text { tissue }\end{array}$ \\
\hline 6 & Female, 25 y & Nodular & Head \& tail & $10 \times 9 \times 8$ & Mild fibrosis \\
\hline
\end{tabular}

* Patients 2,3 and 4 were alcohol users. None had diabetes

** Where multiple nodules were observed, size of the largest nodule is presented

\section{Adrenal glands}

On macroscopic examination, diffuse adrenal gland enlargement, nodular enlargement and cysts were observed in $6(1.6 \%$; 4 bilateral), 7 (1.8\%; 1 bilateral), $2(0.5 \%$; 1 bilateral) respectively. All macroscopic adrenal nodules were measured less than $2 \mathrm{~cm}$ in diameter.

Microscopy of diffusely enlarged adrenal glands were normal in 2, hyperplastic in 3 (all bilateral) and contained caseating granuloma in 1 (bilateral) indi- vidual. Nodular hyperplasia was seen in 2 individuals (1 bilateral) with macroscopically normal adrenal glands. Unilateral adrenal nodules were commoner on the right gland than the left (5 Vs 2), all being benign.

Among those with nodular enlargement of adrenal, only one showed nodular hyperplasia (which was unilateral) in microscopy while in others it was normal. Microscopy of adrenal cysts was normal. No adenomas or carcinomas were found.

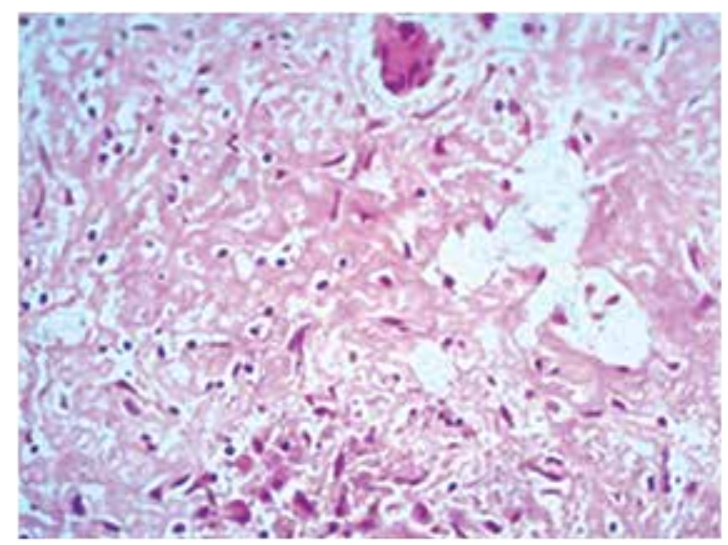

(a)

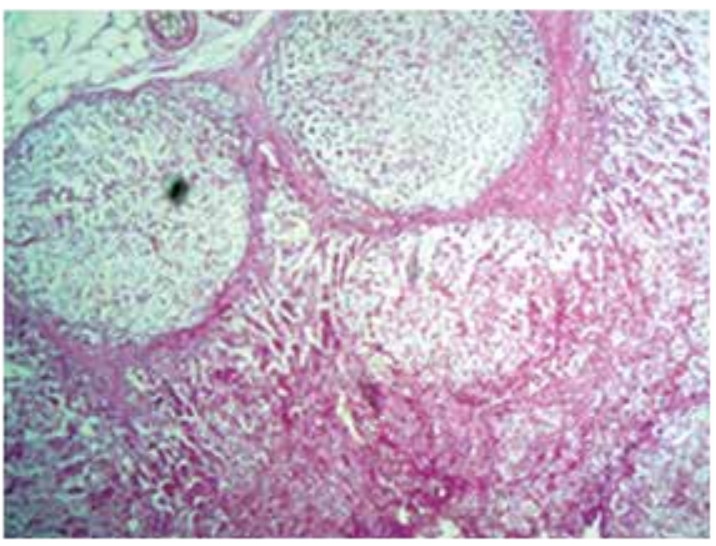

(b)

Figure 3 : (a) Adrenal granuloma (x400); (b) nodular adrenal hyperplasia (x 40) 


\section{Ovaries}

From the available number of specimens for ovarian pathology evaluation $(\mathrm{n}=71), 5(7.0 \%)$ individuals had bilateral multiple ovarian follicular cysts. Unilateral multiple follicular cysts were detected in $6(8.5 \%)$ and $2(2.8 \%)$ in right and left ovaries respectively. One female had bilateral hemorrhagic ovarian cysts. None showed neoplastic features.

\section{Discussion}

To the best of our knowledge, this is the first largescale post-mortem study in Sri Lanka and from a South Asian region investigating the abnormalities of endocrine glands.

Prevalence of pituitary adenoma in this series was $0.8 \%$, lower compared to most other series (15). All of those were microadenomas. Incidence of pituitary adenomas is found to be higher among females and increase with age in other autopsy series (16)[a]. The low rate of pituitary adenomas in our series may be due to lower number of females and relatively young age of the participants in our study. This is because most of our study cohort were recruited from the autopsies done following death after trauma due to road traffic or other accidents

Previously undetected macroscopic thyroid gland abnormalities were detected in $40.1 \%$ of the participants, a rate comparable to previous reports $(17$, 18). Clinically silent occult neoplasms were detected in $6.4 \%$ of the participants. Among those with solitary nodules, $21.8 \%$ were neoplastic. Majority of those with neoplasms had papillary carcinomas (18 of 21). This is a higher rate compared to other autopsy studies where incidence of occult malignancy ranged between $0.45-13 \%(19,20)$.

Higher rates were reported in people from Hiroshima and Nagasaki, in the range of $18.9-28.4 \%$. (21, 22). Similar to our observation,most occult neoplasms were papillary carcinomas (23).

Our study also showed an association between chronic thyroiditis and papillary carcinoma. Similar associations have been shown previously between chronic lymphocytic thyroiditis and papillary carcinoma $(24,25)$.
Prevalence of adrenal nodules were $1.8 \%$ in our series, comparable to previous studies reporting 1.45 $-1.97 \%(26,27)$. However, this is much less compared to a similar study from India where $22.4 \%$ of specimens had adrenocortical incidental nodules (28). Further, we did not find any neoplasms in histological assessment. In fact, all adrenal nodules were smaller than $2 \mathrm{~cm}$ while most malignancies had been observed in adrenal nodules larger than 4 $\mathrm{cm}$ (29). Adrenal incidentalomas are relatively rare and the population studied in our series would have been inadequate to capture those rarities. Furthermore, prevalence of adrenal carcinoma increases with age, affecting only $0.2 \%$ in young and $6.9 \%$ in those 70 years or older (11). Under-representation of older subjects would also have accounted for the lower prevalence of adrenal nodules in this study. In this series, focal lesions of the pancreas were seen in $1.6 \%$ of the individuals, a rate lower than previous reports of $6.1 \%$ (30). Furthermore, none of the focal lesions showed neoplastic changes in histology. In fact, only one neoplastic lesion was noted in the entire series, which was present in a macroscopically normal pancreas. This is notably different from previous studies where, among focal pancreatic lesions, 31\% were malignant and 47\% were pre-malignant (30). However, this observation should be interpreted with caution due to the relatively low number of participants included in this series.

\section{Conclusions}

In this first large-scale autopsy study on endocrine gland abnormalities in Sri Lankan adults, a lower prevalence of pituitary, adrenal and pancreatic incidentalomas was found compared to previous studies from Western and East Asian countries. However, prevalence of thyroid nodules was comparable to other parts of the world, and most were papillary carcinomas, which showed a predilection to affect thyroid glands with background thyroiditis.

\section{Limitation of the study}

There are few limitations in our study. First, special stains or immunohistochemistry studies were not performed due to resource limitations and this limited us from making specific histological diagnoses. 
This may also have contributed to low prevalence of incidentalomas since some small lesions may be missed in H\&E staining. Second, the clinical data were obtained from next of kin and reviewing medical records, which would have concealed subclinical and undiagnosed diseases. Third, the study was carried out on post mortem examinations performed at a judicial medical centre which introduced a selection bias, recruiting more men and relatively young population, since most post mortems were performed due to unnatural deaths (accidents, violence). An older population would have harboured more incidentalomas in endocrine glands. Fourth, relevant biochemical investigations like thyroid functions, HbA1c, pituitary and adrenal hormone profiles could not be performed which would have yielded more useful information. Furthermore, histological assessment to distinguish follicular adenoma from carcinoma could not be performed since the number of sections examined from lesions were limited.

\section{Funding}

This study was supported by a research grant from Medical Research Institute, Colombo 08, Sri Lanka.

\section{Acknowledgement}

Not applicable.

\section{Conflict of interest}

None.

\section{References}

1. Molitch ME, Russell EJ. The pituitary "incidentaloma”. Ann Intern Med. 1990 Jun 15;112(12):92531.

2. Vallecillos FJ, Fernandez SO. Histopathological features of post-mortem pituitaries: A retrospective analysis. Rev Assoc Med Bras. (1992). 1992 SepOct;62(5):399-406.

3. Turner NRM HE, Byrne, J.V., Wass, J.A.H. Pituitary, adrenal and thyroid incidentalomas. Endocrine-RElated Cancer. 1998;5:131-50.
4. Buurman H, Saeger W. Abnormalities in incidentally removed adrenal glands. Endocr Pathol. 2006 Fall;17(3):277-82.

5. Roy TKDK, Das, S, Sarkar, M. Incidental Findings of Pathological Lesions of Adrenal Gland from Routine Autopsy of Medicolegal Cases. International Journal of Contemporary Medical Research. 2018;5(1).

6. Reinhard C, Saeger W, Schubert B. Adrenocortical nodules in post-mortem series. Development, functional significance, and differentiation from adenomas. Gen Diagn Pathol. 1996 Mar;141(34):203-8.

7. Franko J, Feng W, Yip L, Genovese E, Moser AJ. Non-functional neuroendocrine carcinoma of the pancreas: incidence, tumor biology, and outcomes in 2,158 patients. J Gastrointest Surg. 2009 Mar;14(3):541-8.

8. Solnik MJ, Alexander C. Ovarian incidentaloma. Best Pract Res Clin Endocrinol Metab. 2012 Feb;26(1):105-16.

9. Chrisoula D, Scopa, J.P., Spiliotis, J., Melachrinou, M. Autopsy Findings in Clinically Normal Thyroids: A Study in Southwestern Greek Population. International Journal of Surgical Pathology. 1993;1(1):25-32.

10. Osuolale F. A Histological Study of Thyroid Glands in Clinically Asymptomatic Adults at Autopsy. American Journal of Clinical Pathology. 2018;150:S-60.

11. Kloos RT, Gross MD, Francis IR, Korobkin M, Shapiro B. Incidentally discovered adrenal masses. Endocr Rev. 1995 Aug;16(4):460-84.

12. Tanriover O, Comunoglu N, Eren B, Comunoglu C, Turkmen N, Dogan M, et al. Occult papillary thyroid carcinoma:prevalence at autopsy in Turkish people. Eur J Cancer Prev. 2011 Jul;20(4):308-12.

13. Solares CA, Penalonzo MA, Xu M, Orellana E. Occult papillary thyroid carcinoma in postmortem species: prevalence at autopsy. Am J Otolaryngol. 2005 Mar-Apr;26(2):87-90.

14. Mohan Das B.B.J.M. S, B., Chattopadhyay, S. A histopathological study of autopsied thyroid. Thyroid research \& practice. 2017;14(3):112-7. 
15. Molitch ME. Pituitary tumours: pituitary incidentalomas. Best Pract Res Clin Endocrinol Metab. 2009 Oct;23(5):667-75.

16. McDowell BD, Wallace RB, Carnahan RM, Chrischilles EA, Lynch CF, Schlechte JA. Demographic differences in incidence for pituitary adenoma. Pituitary. 2011 Mar;14(1):23-30.

17. Mortensen JD, Woolner LB, Bennett WA. Gross and microscopic findings in clinically normal thyroid glands. J Clin Endocrinol Metab. 1955 Oct;15(10):1270-80.

18. Furmanchuk AW, Roussak N, Ruchti C. Occult thyroid carcinomas in the region of Minsk, Belarus. An autopsy study of 215 patients. Histopathology. 1993 Oct;23(4):319-25.

19. Sampson RJ, Woolner, L.B., Bahn, R.C., Kurland, L.T. Occult thyroid carcinoma in Olmsted County, Minnesota: prevalence at autospy comapred wiht that in Hiroshima and Nagasaki, Japan. Cancer. 1974;34:2072-6.

20. Nishiyama RH, Ludwug, G.K., Thompson, N.W., editor. The prevalence of small papillary thyroid carcinoma in 100 consecutive necropsies in an American population. New York: Grune \& Stratton; 1977.

21. Fukunaga FH, Yatani, R. Geographic phathology of occult thyroid carcinomas. Cancer. 1975;36:10959 .

22. Bondeson L, Ljungberg O. Occult thyroid carcino$\mathrm{ma}$ at autopsy in Malmo, Sweden. Cancer. 1981 Jan 15;47(2):319-23.

23. Tan GH, Gharib H. Thyroid incidentalomas: management approaches to nonpalpable nodules discovered incidentally on thyroid imaging. Ann Intern
Med. 1997 Feb 1;126(3):226-31.

24. Jeong JS, Kim HK, Lee CR, Park S, Park JH, Kang SW, et al. Coexistence of chronic lymphocytic thyroiditis with papillary thyroid carcinoma: clinical manifestation and prognostic outcome. J Korean Med Sci. Aug;27(8):883-9.

25. Dobrinja C, Makovac P, Pastoricchio M, Cipolat Mis T, Bernardi S, Fabris B, et al. Coexistence of chronic lymphocytic thyroiditis and papillary thyroid carcinoma. Impact on presentation, management, and outcome. Int J Surg. Apr;28 Suppl 1:S70-4.

26. Russell RP, Masi AT, Richter ED. Adrenal cortical adenomas and hypertension. A clinical pathologic analysis of 690 cases with matched controls and a review of the literature. Medicine (Baltimore). 1972 May;51(3):211-25.

27. Russi S, Blumenthal HT, Gray SH. Small adenomas of the adrenal cortex in hypertension and diabetes. Arch Intern Med (Chic). 1945 Nov-Dec;76:284-91.

28. Roy K, Das, T.K., Das, S., Sarkar, M. Incidental Findings of Pathological Lesions of Adrenal Gland from Routine Autopsy of Medicolegal Cases. International Journal of Contemporary Medical Research. 2018;5(1).

29. Barzon L, Sonino N, Fallo F, Palu G, Boscaro M. Prevalence and natural history of adrenal incidentalomas. Eur J Endocrinol. 2003 Oct;149(4):273-85.

30. Winter JM, Cameron JL, Lillemoe KD, Campbell KA, Chang D, Riall TS, et al. Periampullary and pancreatic incidentaloma: a single institution's experience with an increasingly common diagnosis. Ann Surg. 2006 May;243(5):673-80; discussion 803. 